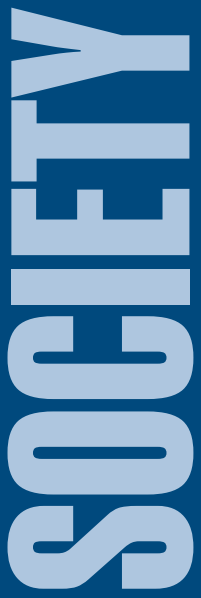

Our goal was to align our structure and programs with the strategic aspirations of the Society - to recognize the unique roles of volunteers and professional staff and to better utilize everyone's talents.

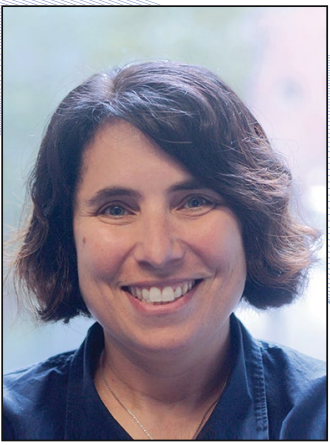

Cherie R. Kagan

2021 MRS President

\section{New governance structure at MRS aims to better serve materials} community

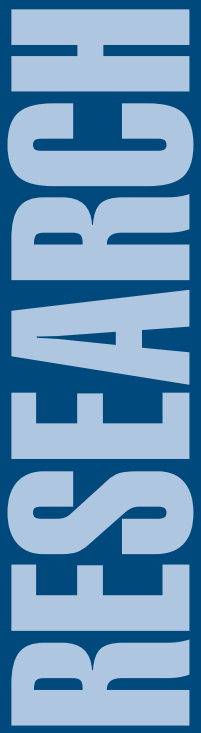

The year 2020 brought about many challenges and changes due to the COVID-19 pandemic. As 2021 begins, we face many of the same issues but also many new opportunities. The circumstances allowed us to focus inward on our community in 2020 and provided a new appreciation for robust scientific exchange and interactions. Within the Materials Research Society (MRS), the number of online webinars and workshops has increased, allowing members from diverse disciplines, interests, and demographic groups from around the world to connect. We have also launched a new publishing alliance with Springer Nature in 2021, providing additional opportunities to connect with others.

While reexamining issues of importance within the Society, we focus on the structure of MRS governance. We aim to streamline governance so that it is more efficient and better capable of serving the MRS community. This affects both the structure of the MRS Board of Directors as well as the Operating Committees. Our goal is to align our structure and programs with the strategic aspirations of the Society - to recognize the unique roles of volunteers and professional staff and to better utilize everyone's talents.

The restructure is a two-year process that started before I became vice president, but in particular, we worked last year through a strategic planning process involving our members as well as the Board and Operating Committees. We engaged a consultant to examine what constitutes good practices for associations. We focused on what is important for MRS through two-way discussions and many meetings.

The MRS Board now has fewer committees: Executive, Finance and Audit, Governance, and Nominating. We decided that these four really represent the responsibilities that we have to the Society. The intention is to allow them to have some functional overlap, so that we can work together to serve the Society as a whole. The Nominating Committee is currently focusing on developing greater diversity in leadership roles. We are also considering the idea of having more task forces, so that we can further engage volunteers.

Our strategic aspiration calls for us to engage members across generations and to focus on advancing their careers. We also want to advance the MRS Mission and promote materials research and innovation: introduce new topics to our Society and publications; ensure we have high-quality meetings; enhance materials research; emphasize the importance of career advancement through networking and career services; and highlight government 
affairs and advocacy. We want volunteers to feel satisfied, engaged, and empowered after participating in activities with the Society.

In thinking forward to 2021 and how we serve our community, we will focus on excellent meetings and publications, opportunities for advocacy of materials research, and other areas where science can positively impact society. Last year has taught us how to meet many challenges and how to escalate the role of science. It has given science a voice and different ways to be heard.

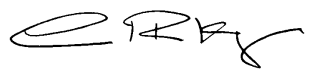

Cherie R. Kagan

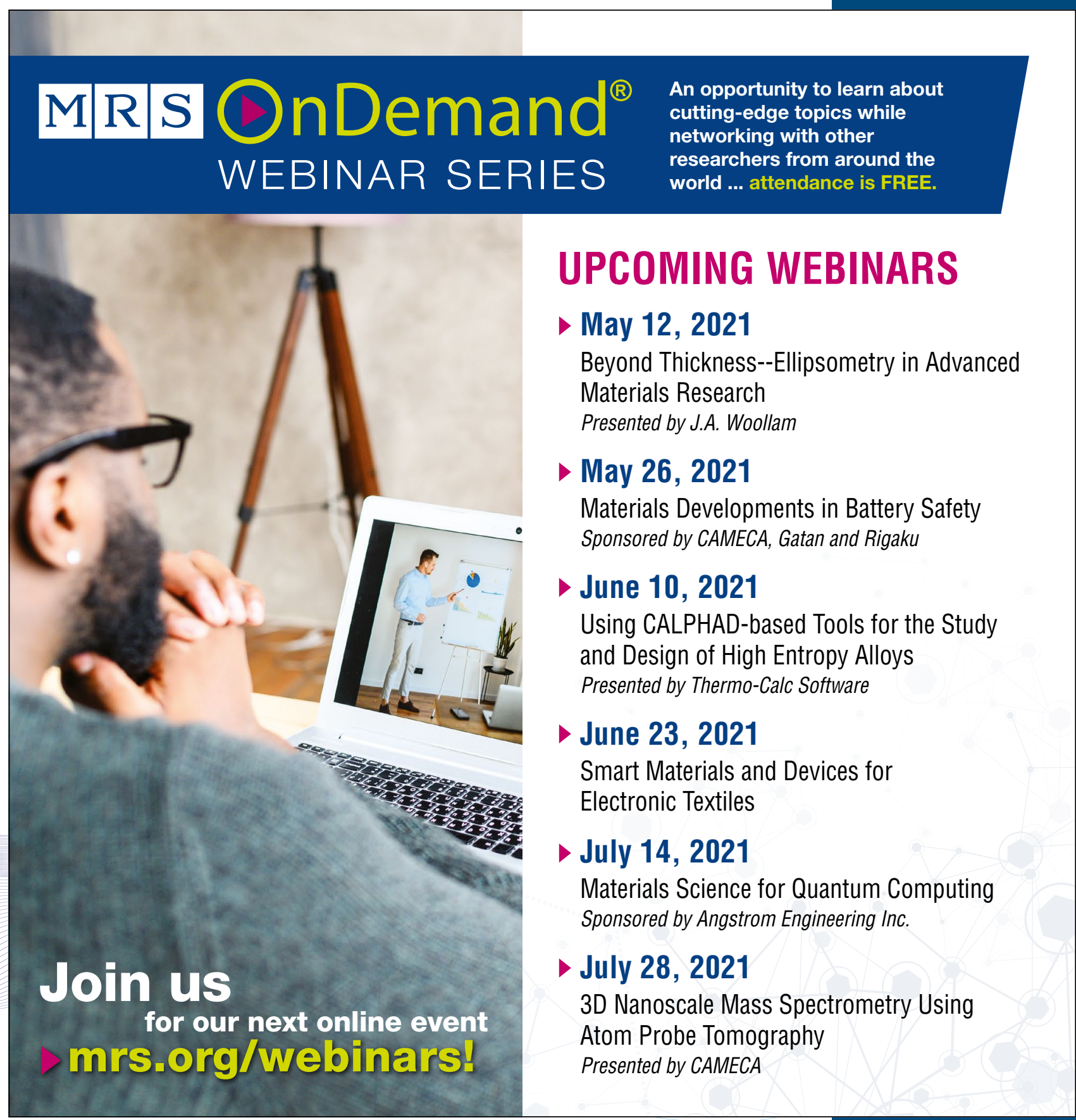

